\title{
US embraces alternative medicine
}

Popular as it is-Americans spend an estimated $\$ 14$ billion a year on alternative medicines and treatments-alternative medicine has surely never attracted more scientific attention than in recent months. Despite director of the National Institute of Health (NIH) Harold Varmus' plea to reduce funding for the Office of Alternative Medicine (OAM), successful government lobbying looks to have achieved a two-thirds increase in the OAM budget to $\$ 20$ million for FY98. The NIH itself spends around $\$ 40$ million on alternative medicine research, such as the recently approved marijuana and St. John's Wort trials. However, last month, at the same time that an NIH consensus meeting was giving acupuncture the thumbs up, the NIH came under fire from John Porter (Rep.-Illinois), who chairs the House of Representatives spending committee that funds it. Porter criticized the organization for not paying enough attention to the practice of "mindbody" medicine - the power of the mind to heal - in which he has become a firm believer since rest and relaxation during the summer months, intead of surgery, "cured" him of a back problem. But alternative medicine is not getting all its own way. Within recent weeks the US Food and Drug Administration has issued warnings about the content of herbal Fen-Phen, and other alternative treatments will soon come under close scientific scrutiny in a new peer-reviewed journal.

\section{Does Sampson see any alternative?}

Scientifically speaking, alternative medicine finally has its official Diogenes: As the founding editor of a new journal, the Scientific Review of Alternative Medicine, Wallace Sampson will be critiquing treatments ranging from acupuncture to yohimbine in his search for those that measure up as scientifically valid.

Sampson, who retired last November as a professor of medicine at Stanford University, has long been an outspoken critic of alternative medicine. With that background, many think that it is a foregone conclusion that his reviews will be negative. "The problem with that question is that it assumes that the only way to evaluate these methods fairly is to have no prior knowledge of them and to know nothing about physiology, physics, chemistry, psychology or sociology," says Sampson. "Anybody with a fair knowledge of these subjects and the ability to evaluate information can form an opinion about these methods. Now, some people would call that a bias, but I call it an informed opinion, and that's what we're after in this journal."

Sampson predicts favorable reviews for some treatments. He cites St. John's wort, touted of late for its ability to relieve depression, as a leading candidate for endorsement: "I'm unable to find anybody who says [it] is phony," says Sampson. As for ginkgo biloba, the Chinese herb recently suggested to be helpful in slowing the progression of Alzheimer's disease, "We'll be looking at it to see what we can find," Sampson says, adding: "Since JAMA reviewed it and found it acceptable, that lessens the likelihood that we would find anything wrong with it."

As for the recent National Institutes of Health's (NIH) consensus development ganized by Alan Trachtenberg, a former head of the Office of Alternative Medicine (OAM) and found the most benefit." conference on acupuncture, Sampson dismisses its endorsement of acupuncture (see box) for a wide range of health problems as entirely predictable. "This was not a consensus development conference; this was a programmed conference intended to validate acupuncture. It doesn't reflect what's known about it by objective scientists in North America and Europe."

The conference, Sampson notes, was or-

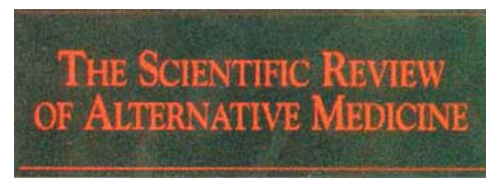

contends, "could adversely affect how projects are designed and carried out and the diligence with which one monitors them through onsite review."

The main problem with the OAM, says Sampson, is that what it does is largely unnecessary. "Proponents of alternative medicine always contend that 'more research is needed' on these topics, and that's the common myth believed by congressmen and other influential people," says Sampson. "The fact is, most of these treatments have been researched, good pasomeone who "has readily admitted to me that he's a proponent of alternative medicine." As a result, says Sampson, "the only invited participants were people I would consider to be proponents of acupuncture. Some of the foremost authorities who are opponents of acupuncture were not even notified." Sampson says the panel "selected and distorted information" and "practiced pseudoscience because they ignored information that contradicted what they believed." He says his own meta-analysis of studies on acupuncture "found that the best papers showed no difference between acupuncture and whatever sham procedure it was compared against, while the worst studies

A persistent critic of the OAM, Sampson is alarmed about recent efforts to upgrade it to a grant-giving center able to appoint its own peer reviewers for projects and to fund them itself. "We already know that proponents of alternative medicine are trying to establish their own criteria, for evaluating research, that are independent of scientific standards," Sampson says. To allow proponents to be peer reviewers, he erature shows that these methods are not of value, which is why they're still regarded as 'alternative.' If they were of value, they would have been accepted by now."

Does Sampson believe OAM should be abolished? "A little part of me says no, because its existence gives the conspiratorial thinkers"-those who believe that organized medicine and the NIH is trying to suppress alternative medicine-"some degree of faith in the system."

But if the office start reporting "negative data" on alternative methods, Sampson predicts a repeat of what happened 15 years ago, when the National Cancer Institute sponsored a clinical study of the purported cancer remedy laetrile and found no benefits, or when Linus Pauling's claims that vitamin $\mathrm{C}$ mega doses helped against cancer were found wanting. "The paranoia will reappear, and the proponents will argue that the studies were done incorrectly. It's as certain a bet as any you'd ever want to make."

LARRY KATZENSTEIN New York 